\title{
Effects of the medicinal plants Curcuma zedoaria and Camellia sinensis on halitosis control
}

\section{Vitor Hugo Farina \\ Ana Paula de Lima \\ Ivan Balducci \\ Adriana Aigotti Haberbeck \\ Brandão}

Department of Biosciences and Oral Diagnosis, São José dos Campos School of Dentistry, Univ Estadual Paulista - UNESP, São José dos Campos, SP, Brazil.
Declaration of Interests: The authors certify that they have no commercial or associative interest that represents a conflict of interest in connection with the manuscript.

Corresponding Author:

Vitor Hugo Farina

E-mail: odontofarina@uol.com.br

Submitted: Apr 11, 2012

Accepted for publication: Jul 02, 2012

Last revision: Jul 16, 2012

\begin{abstract}
Volatile sulphur compounds (VSC) are the gases mainly responsible for halitosis (bad breath). The aim of this research was to evaluate the effects of medicinal plants on halitosis control. Two commonly used plants were tested: Curcuma zedoaria and Camellia sinensis (green tea). These plants were prepared as an aqueous solution and used as mouthwashes, compared with a standard mouthwash of $0.12 \%$ chlorhexidine gluconate and a placebo (water). The experiment was conducted with 30 volunteers from the School of Dentistry of São Jose dos Campos, Univ. Estadual Paulista - UNESP, SP, Brazil. Each volunteer tested the four mouthwashes. The Cysteine Challenge Method, modified for this study, was used for initial breath standardization. Four breath assessments were conducted after volunteers rinsed orally with acetylcysteine: one before the test mouthwash was used; the second, one minute after its use; a third 90 minutes later; and the last 180 minutes later. The results showed that chlorhexidine gluconate lowered VSC production immediately, and that this effect lasted up to 3 hours, while the tested plants had immediate inhibitory effects but no residual inhibitory effects on VSC. We concluded that Curcuma zedoaria and Camellia sinensis, prepared as infusions and used as mouthwashes, did not have a residual neutralizing effect on VSC.
\end{abstract}

Descriptors: Halitosis; Mouthwashes; Curcuma; Camellia sinensis.

\section{Introduction}

Halitosis is a condition frequently characterized by a disagreeable odor emanating from the oral cavity. It mainly affects the adult population, ${ }^{1}$ where its source is intra-oral $(90 \% \text { of cases })^{2}$ or extra-oral $(10 \%$ of cases), and treatment for the latter is much more complicated than that for intra-oral halitosis. Intra-oral halitosis is caused mainly by the action of proteolytic anaerobic Gram-negative bacteria, which reside on the superficial surfaces of the teeth and tongue, and also in the periodontal pockets. ${ }^{3,4}$ The bacteria metabolize amino acids such as methionine, cystine, and cysteine, ${ }^{5}$ resulting in the production of sulphur-containing gases, known as Volatile Sulphur Compounds (VSC), particularly hydrogen sulfide $\left(\mathrm{H}_{2} \mathrm{~S}\right)$ and methyl mercaptan $\left(\mathrm{CH}_{3} \mathrm{SH}\right)$, which are mainly responsible for bad breath (halitosis). ${ }^{1,6}$

Rigorous oral hygiene is recommended for all patients, especially those with halitosis, since its primary origin is oral, and the control of 
bacteria in the mouth is an important tool to combat halitosis. If halitosis persists even after oral hygiene, it is possible that bacterial control is insufficient, in which case patients are advised to gargle and rinse with mouthwashes. ${ }^{7,8}$

It is believed that rinses and toothpastes containing herbal ingredients have anti-plaque and anti-gingivitis activity. Haffajee et al. ${ }^{9}$ tested the effects of herbal, essential oil, and chlorhexidine mouthrinses on the composition of the subgingival microbiota and clinical periodontal parameters in 116 subjects, and observed that all mouthrinses tested produced improvements in clinical parameters in the periodontal maintenance subjects.

This paper discusses the effects of two medicinal plants popularly consumed as tea and indicated for the control of halitosis-Camellia sinensis and Curcuma zedoaria-with the goal of verifying their effects on the production of VSC in vivo.

Some authors have observed antimicrobial effects with extracts of Camellia sinensis in vitro. ${ }^{10,11}$ Lodhia et al. ${ }^{12}$ observed reductions in VSC in vivo immediately after the use of green tea powder, and Zeng and others ${ }^{13}$ observed a reduction in the levels of $\mathrm{CH}_{3} \mathrm{SH}$ and $\mathrm{H}_{2} \mathrm{~S}$ in vitro after the use of a green tea extract.

In vitro studies have demonstrated significant activity of the essential oil of Curcuma zedoaria against Gram-positive and -negative micro-organisms and fungi, ${ }^{14,15}$ as well as low cytotoxicity when fluid extract is used in preparations for oral hygiene, mostly for antiseptic purposes. ${ }^{16}$

Since these two plants are often popularly referred to for the control of halitosis, and on the assumption that they possess antimicrobial activity in the mouth, we used these plants in this study in the form of mouthwashes to assess their ability to reduce the formation of VSC produced by proteolytic bacteria.

\section{Methodology}

This study was performed ethically in accordance with the Declaration of Helsinki (World Medical Association) and was approved by the Committee of Research Ethics of Univ. Estadual Paulista - UNESP, School of Dentistry in the city of São Jose dos Cam- pos, Brazil (protocol number 075/2005-PA/CEP).

Tests were undertaken on 30 volunteer adults of both sexes, between 19 and 43 years of age, all of whom were made fully aware of the terms of consent.

The inclusion criteria included the absence of natural halitosis (VSC below 110 ppb) observed by the measurement of VSC before subjects rinsed with acetylcysteine. Thus, readings above $110 \mathrm{ppb}$ were standardized according to the "Cysteine Challenge Model". ${ }^{17}$ This model uses L-cysteine in a $6-\mathrm{mM}$ aqueous solution at a $\mathrm{pH}$ of 7.2. For this study, Nacetylcysteine was used as a source of cysteine at a concentration of $57 \mathrm{mM}$ at a $\mathrm{pH}$ of 6.1 .

All participants were in good general and periodontal health. They had at least 20 natural teeth, were non-smokers, did not wear orthodontia, were not undergoing any medical treatment, were taking no medication, and were not using oral mouthwashes.

The volunteers tested 4 different mouthwashes:

- Camellia sinensis (green tea),

- Curcuma zedoaria,

- $12 \%$ chlorhexidine gluconate, and

- a placebo (water).

All mouthwashes were alcohol-free. The volunteers used each mouthwash only on the test day, allowing an interval of one week between tests. The participants did not know what substance they were using.

The Camellia sinensis used in the study was manufactured by the phytotherapeutic laboratory Herbarium (Colombo, Brazil). Each individual sachet contained $1.5 \mathrm{~g}$ of ground green tea leaves. The solution of oral mouthwash was prepared by infusion of the sachet in $200 \mathrm{~mL}$ of recently boiled filtered water, where it was allowed to steep for $3 \mathrm{~min}$ utes. The sachet was then removed, and the solution was allowed to cool naturally for 1 hour before being used as a mouthwash.

The Curcuma zedoaria used in the study was manufactured by the phytotherapeutic laboratory Panizza (Taboão da Serra, Brazil). It was supplied in powdered form from the root of the above-mentioned plant. The mouthwash was prepared by de- 
coction, that is, a 2.2-g quantity of the powdered root was placed in $200 \mathrm{~mL}$ of filtered boiling water for 5 minutes, according to the manufacturer's recommendations. The solution was allowed to cool naturally for approximately 1 hour prior to being used as a mouthwash.

As a positive control, a solution of $0.12 \%$ chlorhexidine gluconate was used. No sweetener, flavoring, coloring, or alcohol was added. As a negative control, natural mineral water was used.

To measure the VSC produced by the volunteers, we used a portable sulphur monitor, Halimeter ${ }^{\circledR}$ RH-17K (Interscan Corp., Chatsworth, USA), a device widely used in halitosis research. It is relatively inexpensive, easy to use, has good sensitivity for VSC, especially $\mathrm{H}_{2} \mathrm{~S}$, and has a numeric display that shows the presence of VSC in parts per billion (ppb).

All subjects were advised to avoid spicy foods or strong seasonings (such as onions and garlic) 24 hours before the tests, along with chewing gum, boiled sweets, coffee, breath fresheners, and fragrances 4 hours before the tests. The tests were conducted approximately 1 hour after a meal. Subjects were also advised to avoid any food or drink until the tests were completed.

Tests were divided into 3 phases:

- (a) $1^{\text {st }}$ phase - Each subject rinsed with a $10-\mathrm{mL}$ solution of acetylcysteine for 30 seconds, expectorated, then kept his/her mouth closed for 60 seconds. Breath was monitored (initial instant). One minute later, the patient rinsed his/ her mouth with a $10-\mathrm{mL}$ test solution for 30 seconds. The patient then expectorated and was advised to keep his/her mouth closed for 60 seconds before another breath measurement was taken (final instant - 1), to check the immediate effect of the test. The patient was then advised to return after 90 minutes.

- (b) $2^{\text {nd }}$ phase - Rinsing was repeated with a solution of acetylcysteine, and a new breath measurement (final instant - 2) was taken to test the residual effect 90 minutes after use of the tested solution. The patient was then advised to return after 90 minutes.

- (c) $3^{\text {rd }}$ phase - As in the second phase, undertaken 3 hours after the start of testing, to measure the residual effect after a period of 180 minutes (final instant - 3). The patient was then dismissed.

The statistical analysis of the results obtained presents data for the measured VSC by monitoring the presence of sulphur after subjects rinsed with the different mouthwashes after three consecutive time intervals:

- after 1 minute,

- after 90 minutes, and

- after 180 minutes.

The calculation was made by the difference between the measurements for VSC at the initial instant and at the final instant, and the data were transformed into percentages.

The graphs and Friedman's ANOVA tests (and Dunn's multiple-comparison tests) were made with the computer program GraphPad Prism (version 4.02 for Windows, GraphPad Software, San Diego, USA).

\section{Results}

The results of this study showed that, 1 minute after subjects rinsed with the test mouthwash, there was a reduction in the concentration of VSC (with little variation among the groups). The results with water and Camellia sinensis were similar, being slightly different from those with Curcuma zedoaria, and, to a greater degree, different from those with chlorhexidine (Figure 1A).

Table 1 presents the data in percentages (\%), as well as the results of Dunn's test (to identify similar groups).

Ninety and 180 minutes after subjects rinsed with the test mouthwashes, there was a reduction in the concentration of VSC in the chlorhexidine group. There was an increase in VSC in the remaining groups. The results with water, Camellia sinensis, and Curcuma zedoaria were similar; however, they were different from those of the chlorhexidine group (Figures $1 \mathrm{~B}$ and $1 \mathrm{C}$; Tables 2 and 3 ).

\section{Discussion}

The use of oral mouthwashes to control dental plaque, gingivitis, and halitosis is widespread, in 
tandem with traditional mechanical controls. However, few available commercial products utilize medicinal plants.

In this study, we chose the medicinal plants Curcuma zedoaria and Camellia sinensis to evaluate their effects on the production of VSC. There are many references to these plants in electronic media relating Curcuma zedoaria and green tea to the treatment of halitosis. Also, there are references in the scientific literature describing their medicinal,

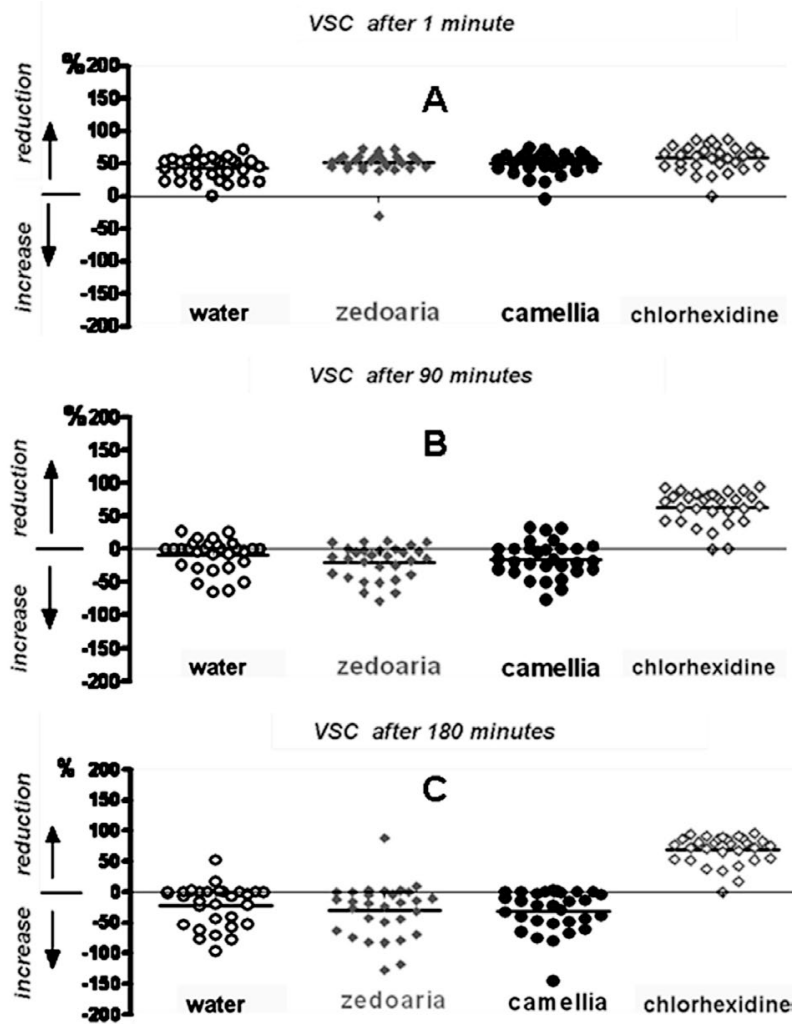

Figure 1 - Dot plot of VSC (\%), obtained from 30 patients using 4 different types of mouthwashes. (A) Results after 1 minute; (B) results after 90 minutes; (C) results after 180 minutes. bactericidal, and fungicidal properties. ${ }^{14,15,18-20}$

In this experiment, the plants were used in their natural state, having undergone no chemical processes such as those used in the preparation of tinctures and organic extracts. This was done because we judged it more appropriate to evaluate the plants' effects in the form commonly used by the public and in the amount recommended by manufacturers for a cup of tea. The plants were used in isolation, without the addition of other chemical or herbal substances, thus avoiding potential interactions such as synergy or antagonism. ${ }^{21}$

Curcuma zedoaria is widely used and has a large margin of safety for human consumption. Ficker et al. ${ }^{14}$ consider that these specimens (from the Zingiberaceae family) are excellent candidates for the development of phytotherapeutic anti-fungals. Sandrini et al. $^{22}$ consider that aqueous solutions of $7.1 \%$ (for mouthwashes), obtained from hydro-alcoholic extracts of Curcuma zedoaria, can be used as auxiliaries for the mechanical control of dental plaque and gingivitis. This is because they present significant anti-inflammatory and antimicrobial properties, and also because of their low toxicity in the form of mouthwashes. Studies by Lai et al. ${ }^{20}$ and by Wilson et al. ${ }^{15}$ conclusively proved their inhibitory action against some Gram-positive and -negative micro-organisms and fungi, by the use of essential oils and extracts of Curcuma zedoaria obtained from different organic solvents. There was no effect when water was used as a solvent.

Navarro et al., ${ }^{23}$ using hydro-alcoholic extracts of Curcuma zedoaria, observed analgesic and antiinflammatory effects in rats, and claimed that many studies have confirmed most of the popular indications for these plants.

Camellia sinensis has effects on a variety of

Table 1 - Results after 1 minute. VSC data (\%) obtained from breath tests in 30 patients using 4 different types of mouthwashes.

\begin{tabular}{l|c|c|c|c|c|c|c}
\hline \multicolumn{1}{c|}{ Mouthwash } & $\mathrm{N}$ & Mean & SD* & Minimum & Median & Maximum & $\mathrm{HG}^{* *}$ \\
\hline Water & 30 & 42.53 & 17.46 & 0 & 47.99 & 71.2 & $\mathrm{~A}$ \\
\hline C. zedoaria & 30 & 51.36 & 17.96 & -30.37 & 54.44 & 73.3 & $\mathrm{~B}$ \\
\hline C. sinensis & 30 & 49.98 & 16.61 & -4.62 & 51.58 & 74.43 & $\mathrm{AB}$ \\
\hline Chlorhexidine & 30 & 58.91 & 20.09 & 0 & 61.86 & 87.95 & $\mathrm{~B}$ \\
\hline
\end{tabular}

*Standard deviation; **Homogenous Groups: Medians followed by different letters represent statistically significant differences between groups. The Dunn test $(5 \%)$ after Friedman's ANOVA $\left(F_{(d f=3)}=23.16 ; p=0.0001<0.05\right)$. 
Table 2 - Results after 90 minutes. Statistical VSC data (\%) obtained from breath tests of 30 patients using 4 different types of mouthwashes.

\begin{tabular}{l|c|c|c|c|c|c|c}
\hline \multicolumn{1}{c|}{ Mouthwash } & $\mathrm{N}$ & Mean & SD* & Minimum & Median & Maximum & HG** $^{* *}$ \\
\hline Water & 30 & -8.94 & 24.27 & -65.2 & 0 & 27.49 & $\mathrm{~A}$ \\
\hline C. zedoaria & 30 & -19.66 & 25.34 & -78.95 & -12.99 & 12.2 & $\mathrm{~A}$ \\
\hline C. sinensis & 30 & -15.45 & 26.61 & -76.6 & -17.39 & 33.23 & $\mathrm{~A}$ \\
\hline Chlorhexidine & 30 & 63.53 & 25.48 & 0 & 73.05 & 94.36 & $\mathrm{~B}$ \\
\hline
\end{tabular}

*Standard deviation; **Homogenous Groups: Medians followed by different letters represent statistically significant differences between groups. The Dunn test $(5 \%)$ after Friedman's ANOVA $\left(F_{(d f=3)}=49.30 ; p=0.0001<0.05\right)$.

\begin{tabular}{|c|c|c|c|c|c|c|c|c|}
\hline \multirow{5}{*}{$\begin{array}{r}\text { Table } 3 \text { - Results after } 180 \\
\text { minutes. Statistical VSC data (\%) } \\
\text { obtained from breath tests from } 30 \\
\text { patients using } 4 \text { different types of } \\
\text { mouthwashes. }\end{array}$} & Mouthwash & $\mathrm{N}$ & Mean & SD* & Minimum & Median & Maximum & $\mathrm{HG}^{* *}$ \\
\hline & Water & 30 & -22.08 & 33.68 & -96.91 & -7.49 & 52.00 & A \\
\hline & C. zedoaria & 30 & -30.17 & 43.38 & -127.29 & -17.74 & 88.24 & A \\
\hline & C. sinensis & 30 & -31.09 & 33.68 & -145.24 & -22.16 & 2.80 & A \\
\hline & Chlorhexidine & 30 & 68.80 & 23.80 & 0 & 76.65 & 96.86 & B \\
\hline
\end{tabular}

micro-organisms, and although the mechanism is unclear, the potential of Epigallocatechin gallate (EGCg), the main antimicrobial tea catechin, in reducing periodontal disease has been suggested. ${ }^{18} \mathrm{Xu}$ et al. ${ }^{19}$ studied in vitro the inhibitory effects of EGCg and found that it inhibited bacterial growth and was bactericidal. At sub-MIC levels, EGCg inhibited $\mathrm{CH}_{3} \mathrm{SH}$ production, mgl mRNA, and protein expression. They concluded that EGCg may represent a natural and alternative agent to the antimicrobial chemicals currently available for halitosis control.

Matsumoto et al., ${ }^{11}$ studying the effects of extracts of Camellia sinensis, observed that several bacteria and fungi were sensitive to the extracts. Among them were Escherichia coli and strains of Staphylococcus aureus.

Researching the anti-cariogenic activity of green tea, Sakanaka et al. ${ }^{10}$ verified that a metanolic extract of tea inhibits the growth of the bacterium Streptococcus mutans. Besides the possible control and prevention of infections in humans, principally caries, the cited authors consider tea from Camellia sinensis a functional food for oral health.

The above studies indicate that perhaps the aqueous extracts of both plants are not ideal to prevent the presence of micro-organisms in the mouth, since the extracts obtained from organic solvents produce more efficient microbiological results. Similar con- clusions were obtained by Lauten et al., ${ }^{21}$ by testing an herbal mouthwash with Camellia sinensis in its composition. Furthermore, among the micro-organisms sensitive to the plant extracts, only a limited number are VSC producers and frequently found in periodontal disease.

Studying chemical compositions, Saito et al. ${ }^{24}$ compared the Camellia sinensis teas produced by a Brazilian company with samples of teas produced in Japan and China. They concluded that the quantities of EGCg found in the Brazilian green teas were greater than the quantities found in black tea produced in the same region of Brazil, and also greater than in the imported green teas. This could be due to differences in climate and soil in Brazil and also to the variety cultivated.

One important factor to be considered in our study, in analysis of the experimental results, is the fact that plants in general are very sensitive to environmental variations, and their biological properties are influenced by climate, biodiversity, botanical varieties, and drying periods, and therefore may not always present the necessary therapeutic effects.

All study participants had good periodontal health, and hence their oral flora contained low numbers of the bacteria that cause periodontal illnesses. For that reason, most of the VSC production observed in the participants, after rinsing with acet- 
ylcysteine, was the result of the action of proteolytic micro-organisms, perhaps present on the tongue, ${ }^{4}$ that were not sensitive to phytotherapeutic mouthwashes.

The results of our tests showed that topical action of aqueous extracts of Curcuma zedoaria and Camellia sinensis had immediate inhibitory effects and no residual inhibitory effects on the production of VSC in vivo during the periods tested.

Since these two medicinal plants are popularly consumed as tea and indicated for the control of halitosis, one hypothesis to consider is that their related anti-halitosis action could also be due to the ingestion of teas, not only because of their topical effects. If this is true, investigation concerning the systemic effects of tea is necessary, particularly since these plants are also used in the treatment of digestive problems.

\section{Conclusions}

From the obtained results and within the experi-

\section{References}

1. Tonzetich J. Production and origin of oral malodor: a review of mechanisms and methods of analysis. J Periodontol. 1977 Jan;48(1):13-20.

2. Sanz M, Roldán S, Herrera D. Fundamentals of breath malodour. J Contemp Dent Pract. 2001 Nov;2(4):1-17.

3. McNamara TF, Alexander JF, Lee M. The role of microorganisms in the production of oral malodor. Oral Surg Oral Med Oral Pathol. 1972 Jul;34(1):41-8.

4. De Boever EH, Loesche WJ. Assessing the contribution of anaerobic microflora of the tongue to oral malodor. J Am Dent Assoc. 1995 Oct;126(10):1384-92.

5. Tonzetich J, Kestenbaum RC. Odour production by human salivary fractions and plaque. Arch Oral Biol. 1969 Jul;14(7):81527.

6. Lee CH, Kho HS, Chung SC, Lee SW, Kim YK. The relationship between volatile sulfur compounds and major halitosisinducing factors. J Periodontol. 2003 Jan;74(1):32-7.

7. Morita M, Wang HL. Association between oral malodor and adult periodontitis: a review. J Clin Periodontol. 2001 Sep;28(9):813-9.

8. Gunsolley JC. Clinical efficacy of antimicrobial mouthrinses. J Dent. 2010 Jun;38(Suppl 1):S6-10.

9. Haffajee AD, Roberts C, Murray L, Veiga N, Martin L, Teles RP, et al. Effect of herbal, essential oil, and chlorhexidine mouthrinses on the composition of the subgingival mi- mental conditions of this research, it was possible to conclude that the aqueous extractions of Camellia sinensis and Curcuma zedoaria (used as oral mouthwashes), in the chosen concentrations, had immediate inhibitory effects and no residual inhibitory effects on the production of VSC in vivo (after both 90 and 180 minutes). The results obtained here do not preclude further study relative to the effects of these plants on halitosis. Therefore, further experiments, in vitro and in vivo, are needed. These experiments will also require the support of further research concerning adequate standardization of botanical varieties, methods of cultivation and harvesting/processing, and extraction of the required components of these plants.

\section{Acknowledgments}

We would like to express our sincere gratitude to Professor Maria Nadir Gasparoto Mancini (in memoriam)

crobiota and clinical periodontal parameters. J Clin Dent. 2009;20(7):211-7.

10. Sakanaka S, Kim M, Taniguchi M, Yamamoto T. Antibacterial substances in Japanese green tea extract against Steptococcus mutans, a cariogenic bacterium. Agric Biol Chem.1989;53(9):2307-11.

11. Matsumoto Y, Kaihatsu K, Nishino K, Ogawa M, Kato N, Yamaguchi A. Antibacterial and antifungal activities of new acylated derivatives of epigallocatechin gallate. Front Microbiol. 2012;3:53. Epub 2012 Feb 16.

12. Lodhia P, Yaegaki K, Khakbaznejad A, Imai T, Sato T, Tanaka $\mathrm{T}$, et al. Effect of green tea on volatile sulfur compounds in mouth air. J Nutr Sci Vitaminol. 2008 Feb;54(1):89-94.

13. Zeng QC, Wu AZ, Pika J. The effect of green tea extract on the removal of sulfur-containing oral malodor volatiles in vitro and its potential application in chewing gum. J Breath Res. 2010 Sep;4(3):036005. Epub 2010 Aug 27.

14. Ficker CE, Smith ML, Susiarti S, Loeman DJ, Irawati C, Arnoson JT. Inhibition of human pathogenic fungi by members of zingiberaceae used by the Kenyah (Indonesian Borneo). J Ethnopharmacol. 2003 Apr;85(2-3):289-93.

15. Wilson B, Abrahan G, Manju VS, Mathew M, Vimala B, Sundaresan S, et al. Antimicrobial activity of Curcuma zedoaria and Curcuma malabarica tubers. J Ethnopharmacol. 2005 May;99(1):147-51. 
16. Fernandes JP, Mello-Moura AC, Marques MM, Nicoletti MA. Citotoxicity evaluation of Curcuma zedoaria (Christm.) Roscoe fluid extract used in oral hygiene products. Acta Odontol Scand. 2012 Jan 18. [Epub ahead of print].

17. Kleinberg I, Codipilly M. Modeling of the oral malodor system and methods of analysis. Quintessence Int. 1999 May;30(5):357-69.

18. Venkateswara B, Sirisha K, Chava VK. Grenn tea extract for periodontal health. J Indian Soc Periodontal. 2011 Jan;15(1):18-22.

19. Xu X, Zhou XD, Wu CD. Tea catechin EGCg suppresses the $\mathrm{mgl}$ gene assossiated with halitosis. J Dent Res. 2010 Nov;89(11):1304-8.

20. Lai EY, Chyau CC, Mau JL, Chen CC, Lai YJ, Shih CF, et al. Antimicrobial activity and cytotoxicity of the essential oil of Curcuma zedoaria. Am J Chin Med. 2004;32(2):281-90.
21. Lauten JD, Boyd L, Hanson M B, Lillie D, Gullion C, Madden TE. A clinical study: melaleuca, manuka, calendula and green tea mouth rinse. Phytother Res. 2005 Nov;19(11):951-7.

22. Sandrini JC, Navarro DF, Rocha JCF, Ribeiro PG, Koslowski Jr VA. Efeitos do extrato de Curcuma zedoaria sobre a placa dental e gengivite em humanos - avaliação clínica. Rev Periodontol. 1997;6(supl):3-7.

23. Navarro DF, Souza MM, Neto RA, Golin V, Niero R, Yunes RA, et al. Phytochemical analysis and analgesic properties of Curcuma zedoaria grown in Brazil. Phytomedicine. 2002 Jul;9(5):427-32.

24. Saito ST, Welzel A, Suyenaga ES, Bueno F. A method for fast determination of epigallocatechin gallate (EGCG), epicatechin (EC), catechin (C) and caffeine (CAF) in green tea using HPLC. Ciênc. Tecnol Aliment. 2006 Apr-Jun;26(2):394-400. 